\title{
Mono-alkyl Phosphinic Acids as Ligands in Nanocrystal Synthesis
}

Evert Dhaene, ${ }^{1}$ Philippe F. Smet, ${ }^{2}$ Klaartje De Buysser, ${ }^{1}$ Jonathan De Roo ${ }^{3 *}$

${ }^{1}$ Department of Chemistry, Ghent University, Gent B-9000, Belgium

2 Department of Solid State Sciences, Ghent University, Gent B-9000, Belgium

${ }^{3}$ Department of Chemistry, University of Basel, Basel CH-4058, Switzerland

* Corresponding author: Jonathan De Roo, Jonathan.DeRoo@unibas.ch 


\begin{abstract}
Surfactants play a crucial role in the synthesis of colloidal nanocrystals. Nevertheless, only a handful molecules are currently used, oleic acid being the most typical example. Here, we show that mono-alkyl phosphinic acids are an interesting surfactant class with a reactivity that is intermediate between carboxylic acids and phosphonic acids. We first present the synthesis of n-hexyl, 2-ethylhexyl, $n$-tetradecyl, $n$-octadecyl, and oleyl phosphinic acid. These compounds are suitable surfactants during high-temperature nanocrystal synthesis $\left(240-300^{\circ} \mathrm{C}\right)$. In contrast to phosphonic acids, they do not form poly anhydride gels. Consequently, CdSe quantum dots synthesized with octadecylphosphinic acid are conveniently purified, and are free from background scattering in UV-Vis. The CdSe nanocrystals have a very low polydispersity and a photoluminescence quantum yield up to $18 \%$, without additional shell. Furthermore, we could synthesize CdSe and CdS nanorods using phosphinic acid ligands and found a remarkable purity (i.e. without tetrapod impurities). We conclude that the reactivity towards TOP-S and TOP-Se precursors decreases in the series: cadmium carboxylate > cadmium phosphinate > cadmium phosphonate. By introducing a third and intermediate class of surfactants, we enhance the versatility of surfactant-assisted syntheses.
\end{abstract}

\title{
Keywords
}

Nanocrystals, quantum dots, nanorods, ligands, phosphinic acids, surface chemistry 


\section{Introduction}

Colloidal nanocrystals (NCs) are composed of nanosized $(<100 \mathrm{~nm})$ inorganic crystalline cores, capped with (in)organic ligands on the surface. ${ }^{1-2}$ The most common organic ligands used in nanocrystal synthesis are surfactants, with long alkyl chains and a polar binding group. For very small nanocrystals the classical concepts of colloidal stability do not apply and such nanocrystals have an equilibrium solubility. The colloidal solubility is determined by the binding group and the alkyl chain of the surfactant, the nanocrystal core size and the solvent. ${ }^{3-}$ ${ }^{8}$ Controlling the surface chemistry has proven key to many (if not all) nanocrystal applications. ${ }^{2,9}$ Apart from providing solubility to the final nanocrystals, surfactants also play an important role in nanocrystal synthesis, regulating the nucleation and growth rates. ${ }^{9-11}$

Despite the crucial role of ligands, it is striking that most colloidal synthesis methods use the same type of surfactants: oleic acid, oleylamine and octadecylphosphonic acid being the most common. While thiols are great ligands for metals, ${ }^{12}$ and metal chalcogenides, ${ }^{13}$ they are not thermally stable. Indeed, they are often used as a sulphur precursor. ${ }^{14}$ Metal oleates are stable metal precursors for quantum dot syntheses at relatively low temperatures $\left(240{ }^{\circ} \mathrm{C}\right) \cdot{ }^{15-16} \mathrm{At}$ higher temperatures they often decompose to metals or metal oxides. ${ }^{17-18}$ Oleylamine is a typical L-type ligand and binds usually in a dynamic fashion. ${ }^{19}$ In very specific systems, oleylamine can be a tightly bound ligand. ${ }^{20-21}$ Phosphonates and phosphates are among the strongest ligands available and easily displace carboxylic acids, ${ }^{13,22-23}$ especially when designed as multidentate ligands on a scaffold. ${ }^{24-25}$ Phosphonic acids are the ligands of choice for high temperature (> $300{ }^{\circ} \mathrm{C}$ ) quantum dot syntheses. Wurtzite CdSe quantum dots were made by Owen et al using n-octadecylphosphonic acid. ${ }^{26}$ Peng et al. used saturated phosphonic acids to synthesize CdE $\left(\mathrm{E}=\mathrm{S}, \mathrm{Se}\right.$ or Te) nanorods. ${ }^{27}$ Carbone et al. used this strategy to obtain CdSe/CdS dot-in-rod structures. ${ }^{28}$ Motivated by these reports, we recently developed the synthesis of a library of 
phosphonic acid ligands, ${ }^{23}$ including the highly soluble oleylphosphonic acid. Later, Zhang et al. used oleylphosphonic acid to synthesize $\mathrm{CsPBr}_{3}$ nanocrystals. ${ }^{29}$ Although phosphonic acids allow thus to make a variety of nanocrystal (hetero)structures, they are not without a drawback. Phosphonic acids dehydrate at high temperatures, forming phosphonic acid anhydride and water, see scheme $1 .^{30}$

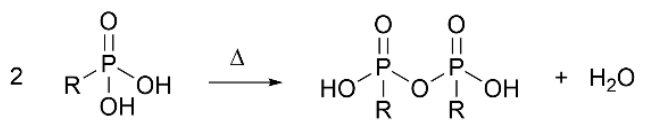

Scheme 1. Dehydration of phosphonic acids.

Since phosphonic acids have two $\mathrm{OH}$ moieties, this reaction can proceed further, forming a polymer, and finally resulting in a macroscopic gel. ${ }^{30}$ The released water molecules can react with the sensitive precursors used in the synthesis. ${ }^{31}$ These may be some of the reasons why reproducing certain nanocrystal reactions can prove challenging.

Another origin of irreproducibility is the use of impure reagents. In 2008, Wang et al. discovered the role of di- $n$-octylphosphinic acid and $n$-octylphosphinic acid on the formation of CdSe nanorods and nanowires. ${ }^{32-34}$ These molecules where present as impurities in commercially available tri- $n$-octylphosphine oxide (TOPO). Although phosphinic acids were thus clearly an alternative ligand class, they received little further attention. ${ }^{35}$ Recently, Kovalenko et al. synthesized $\mathrm{CsPb}_{3}$ from $\mathrm{PbBr}_{2}$, didodecyldimethylammonium halide and cesium di-isooctylphosphinate. ${ }^{36}$ This is a rare use of a phosphinic acid in nanocrystal synthesis and the di-alkyl phosphinate did not end up as a ligand on the nanocrystals surface, presumably due to its high steric hindrance. ${ }^{37-38}$ Mono-substituted alkylphosphinic acids have not yet been explored in nanocrystal synthesis.

Here, we put forward mono-alkyl phosphinic acids as a fully-fledged ligand class, similar to carboxylic acids and phosphonic acids. After presenting the synthesis for several selected 
substrates, we proceed to show the intermediate reactivity of the phosphinic acids in CdSe quantum dot syntheses. The nanocrystals synthesized with phosphinic acids are also easier to purify since there is no gel formation. Very small $(2-3 \mathrm{~nm})$ CdSe quantum dots with low polydispersity and high photoluminescence quantum yields can be easily accessed with phosphinic acids ligands. CdSe and CdS nanorods were also synthesized using phosphinic acids, whereby the rods showed remarkable purity and uniformity. We have thus presented a ligand class that is truly a worthy alternative to carboxylic acids and phosphonic acids, as Xtype ligands in nanocrystal synthesis.

\section{Results and Discussion}

Phosphinic acid synthesis. To synthesize mono-alkyl phosphinic acids, suitable as ligands for nanocrystal synthesis, we identified two main methods. ${ }^{39}$ Method I involves the addition of an alkene to hypophosphorous acid $\left(\mathrm{H}_{3} \mathrm{PO}_{2}\right)$ or sodium hypophosphite $\left(\mathrm{NaH}_{2} \mathrm{PO}_{2}\right)$. Double alkylation can occur and is typically avoided by an excess of phosphorus reagent. Several variations exist with different radical initiators, solvents and reagents concentrations. ${ }^{32,39-42} \mathrm{We}$ found the general protocol of Montchamp et al. (Scheme 2) most convenient to synthesize our target compounds; $n$-hexyl-, $n$-tetradecyl-, and n-octadecylphosphinic acid. The method can be easily performed on multigram scale and uses inexpensive reagents. We recrystallized the products to a high purity (>99\%). 


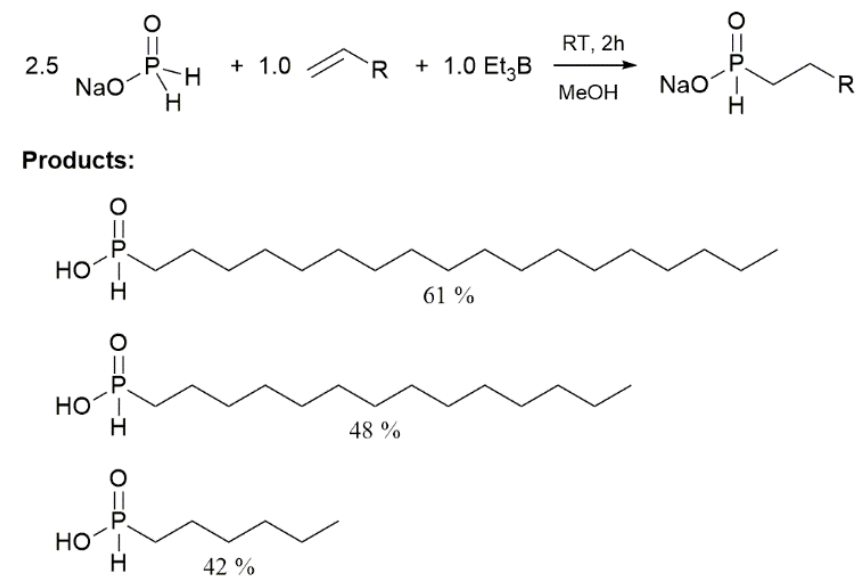

Scheme 2. Method I to synthesize mono $n$-alkyl phosphinic acids and the obtained products with the yield indicated.

We also targeted more complex phosphinic acids such as oleylphosphinic acid and 2ethylhexylphosphinic acid. Indeed, the oleyl fragment is ubiquitous in nanocrystals synthesis due to its high solubility and the high colloidal solubility it provides to nanocrystals. Also a branched chain provides very high colloidal solubility as recently shown by Peng et al. ${ }^{3}$ To synthesize oleylphosphinic acid we first prepared the corresponding terminal alkene, since it is not commercially available. We preferred to start by reducing oleic acid to oleyl alcohol to avoid the trans isomer (E double bond) present in technical oleyl alcohol. The reduction is performed with $\mathrm{Li}\left[\mathrm{AlH}_{4}\right]$ according to Grela et al. ${ }^{43}$ The alcohol was subsequently transformed in either a mesylate or a bromide to function as a good leaving group during the $\mathrm{E}_{1}$ elimination towards the terminal alkene. ${ }^{44-45}$ Upon addition of $\mathrm{KO}^{t} \mathrm{Bu}$, oleyl mesylate remained stable but oleyl bromide fully converted to the terminal alkene. Subsequently, method I yielded a mixture of the desired linear oleylphosphinic acid and the undesired, branched octadec-1-en-9ylphosphinic acid. For this reason, we used method II, where the oleylbromide is turned into a Grignard reagent and reacts with diethyl chlorophosphite (Scheme 3). ${ }^{39,46}$ Both the oleyl and the branched compound cannot be recrystallized and are conveniently purified by column chromatography as the ethyl ester, before being hydrolysed to the target product. 


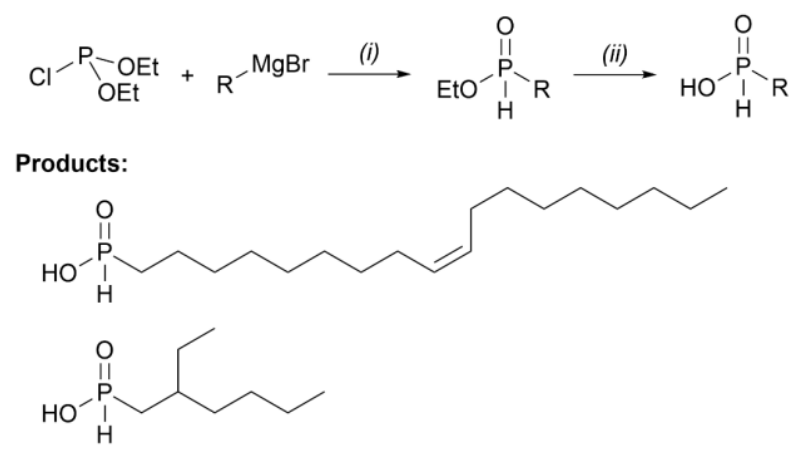

Scheme 3. Method II to synthesize more complex phosphinic acids and the obtained products. Conditions: (i) overnight at $50{ }^{\circ} \mathrm{C}$ in dry THF, then $2 \mathrm{~h}$ at room temperature in conc. $\mathrm{HCl}$ and water. (ii) $1.15 \mathrm{eq}$ of $\mathrm{TMS}-\mathrm{Br}$, overnight in dry DCM, then dry $\mathrm{MeOH}, 6 \mathrm{~h}, 40^{\circ} \mathrm{C}$.

CdSe quantum dot synthesis. Wurtzite CdSe quantum dots are typically synthesized at $300^{\circ} \mathrm{C}$ from cadmium phosphonate, which is formed in situ from cadmium oxide and phosphonic acid. Several groups reported the formation of poly(phosphonic acid anhydride) by-product (Scheme 1), which forms a macroscopic gel, trapping the quantum dots. ${ }^{26,28,30}$ Drijvers et al. managed to significantly reduce the formation of this poly(phosphonic acid anhydride) upon addition of oleyl alcohol to the reaction. ${ }^{30}$ The alcohol forms an ester with one of the two hydroxyl groups of the phosphonic acid, thus inhibiting polymer formation. We hypothesize that we avoid the problem entirely by using mono-alkyl phosphinic acids.

Similar to the phosphonic acid based strategy of Owen et al.,${ }^{26}$ we first dissolved $\mathrm{CdO}$ with two equivalents of octadecylphosphinic acid in TOPO. Phosphinic acid requires higher temperatures to dissolve the $\mathrm{CdO}$, compared to phosphonic acid. This is most likely due to the lower acidity of phosphinic acid ( $\mathrm{pKa}$ in $\mathrm{H}_{2} \mathrm{O} \sim 3.1$ ) compared to phosphonic acid ( $\mathrm{p} K \mathrm{a}$ in $\mathrm{H}_{2} \mathrm{O}$ $\sim 2.4$ and 7.7). ${ }^{47}$ After dissolution of $\mathrm{CdO}$, TOP-Se is injected at $300{ }^{\circ} \mathrm{C}$ and CdSe quantum dots are rapidly formed (Figure 1). After 10 minutes the reaction mixture is cooled down and the nanocrystals are easily purified by precipitation/redispersion cycles with acetone/toluene as antisolvent/solvent. We did not observe any oils or gels. Although the nanocrystals have already ripened (see further), the size dispersion is still quite low; $8 \%$ (size according to TEM: $3.46 \pm$ 
$0.28 \mathrm{~nm}(\mu \pm \sigma))$, see Figure 1B and Figure S1. The nanocrystals have the wurtzite crystal structure, see Figure 1C. The nanocrystal dispersion is free from impurities as attested by NMR. In the ${ }^{1} \mathrm{H}$ NMR spectrum we observe the broadened signature of a bound alkyl chain. ${ }^{48}$ In Diffusion Ordered Spectroscopy (DOSY), we find only a single diffusing species (apart from toluene), see Figure 1D. The diffusion coefficient is $93.78 \pm 0.16 \mu \mathrm{m}^{2} \mathrm{~s}^{-1}$, corresponding to a solvodynamic diameter of $7.8 \mathrm{~nm}$ (which agrees quite well with the nanocrystal core size + twice the length of octadecylphosphinate (approx. $2 \mathrm{~nm}$ ). We find no evidence of a polymeric impurity while we clearly find this impurity in the DOSY spectrum of CdSe quantum dots synthesized with octadecylphosphonic acid (Figure S2). In the ${ }^{31} \mathrm{P}$ NMR spectrum, we observe a broadened resonance of bound ligands (Figure S3).
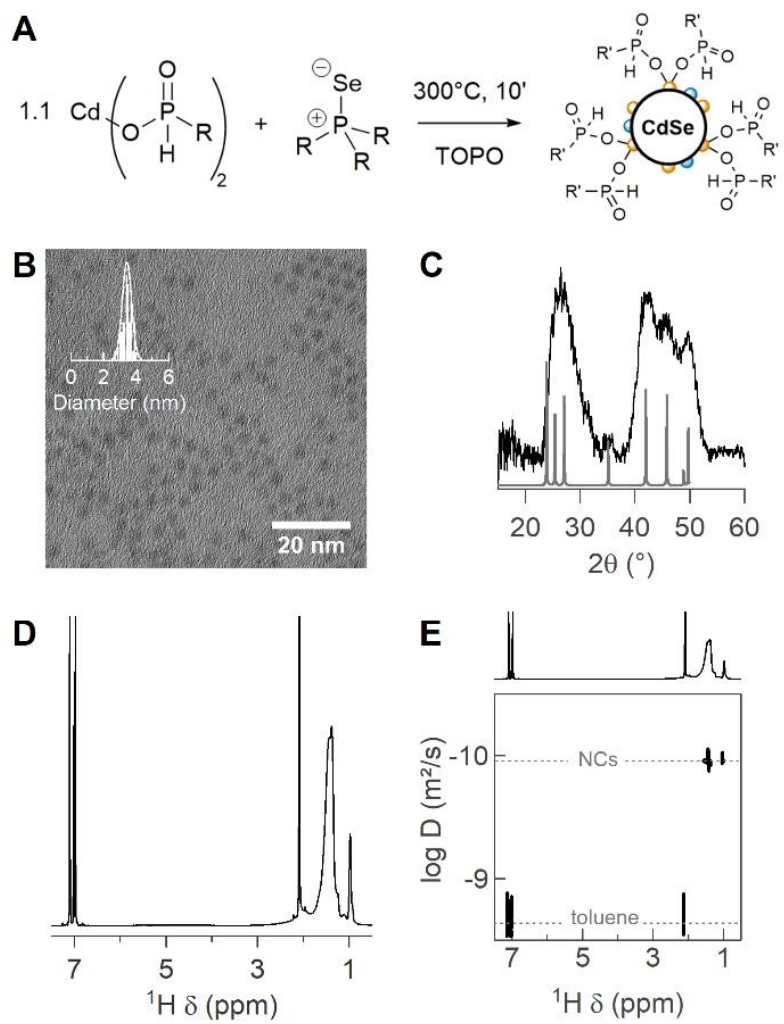

Figure 1. CdSe quantum dots synthesized with $n$-octadecylphosphinic acid. (A) general reaction scheme, (B) TEM image with histogram, (C) x-ray analysis with wurtzite CdSe reference, (D) ${ }^{1} \mathrm{H}$ NMR spectrum, and (E) DOSY NMR spectrum. 
Comparing kinetics with phosphonic and carboxylic acid ligands. According to UV-Vis, the final CdSe quantum dots synthesized with phosphonic acid $(5.4 \mathrm{~nm})$ are larger than the ones synthesized with phosphinic acids $(3.3 \mathrm{~nm})$ (Figure S4). This could be related to the precursor conversion kinetics of the reactions since it is established that faster reactions yield more, but smaller, particles. ${ }^{15,49}$ To investigate this in more detail, we followed the reaction kinetics and also compared with carboxylic acid (Figure 2). We took several reaction aliquots, quantified and diluted them for quantitative UV-Vis analysis. The nanocrystal size was calculated from the position of the first excitonic peak, and the absorption at $340 \mathrm{~nm}$ was used to determine the yield. ${ }^{50}$ From the yield and the size, we calculate the number of particles. We performed this analysis at $300{ }^{\circ} \mathrm{C}$ for both phosphinic and phosphonic acid ligands, and at $240{ }^{\circ} \mathrm{C}$ for both phosphinic and carboxylic acid ligands. These temperatures were chosen since $300{ }^{\circ} \mathrm{C}$ is the common reaction temperature for phosphonic acid ligands, and $240{ }^{\circ} \mathrm{C}$ is common for carboxylic acids.

For phosphonic acids, the yield shows comparable kinetics as reported before for the used $\mathrm{Cd}$ :Se stoichiometry (Figure 2). ${ }^{51}$ After an induction time (where no particles are observed), the number of particles increases over the course of the reaction suggesting continuous nucleation instead of burst nucleation. Continuous nucleation was recently found to be a quite general feature of nanocrystal synthesis, applicable to Ir, Pd, InP and CdSe nanocrystals. ${ }^{10,52-54}$ The particles grow steadily from 3.4 to $5.4 \mathrm{~nm}$, while the polydispersity slightly increases. Given the difficulty in calculating an exact polydispersity from UV-Vis, we choose to present the valley-to-peak ratio, as a measure for the polydispersity. 


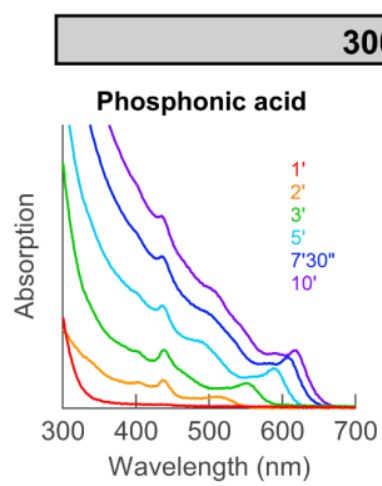

\section{$300^{\circ} \mathrm{C}$}
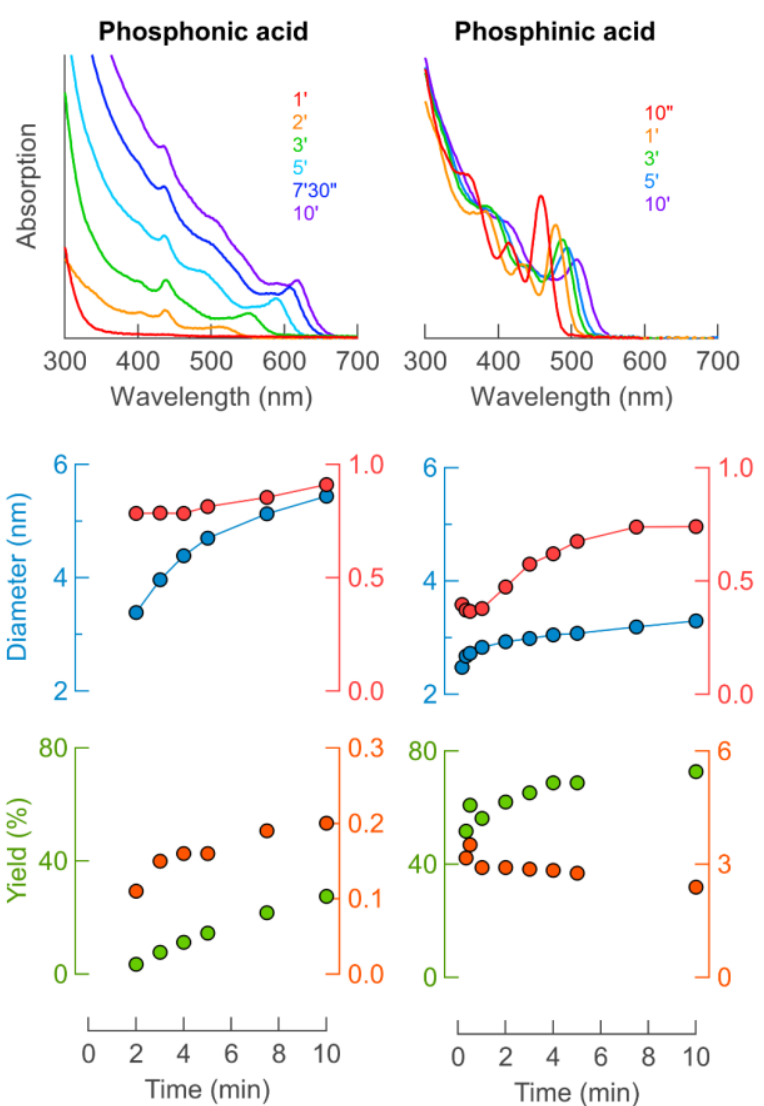

$240^{\circ} \mathrm{C}$
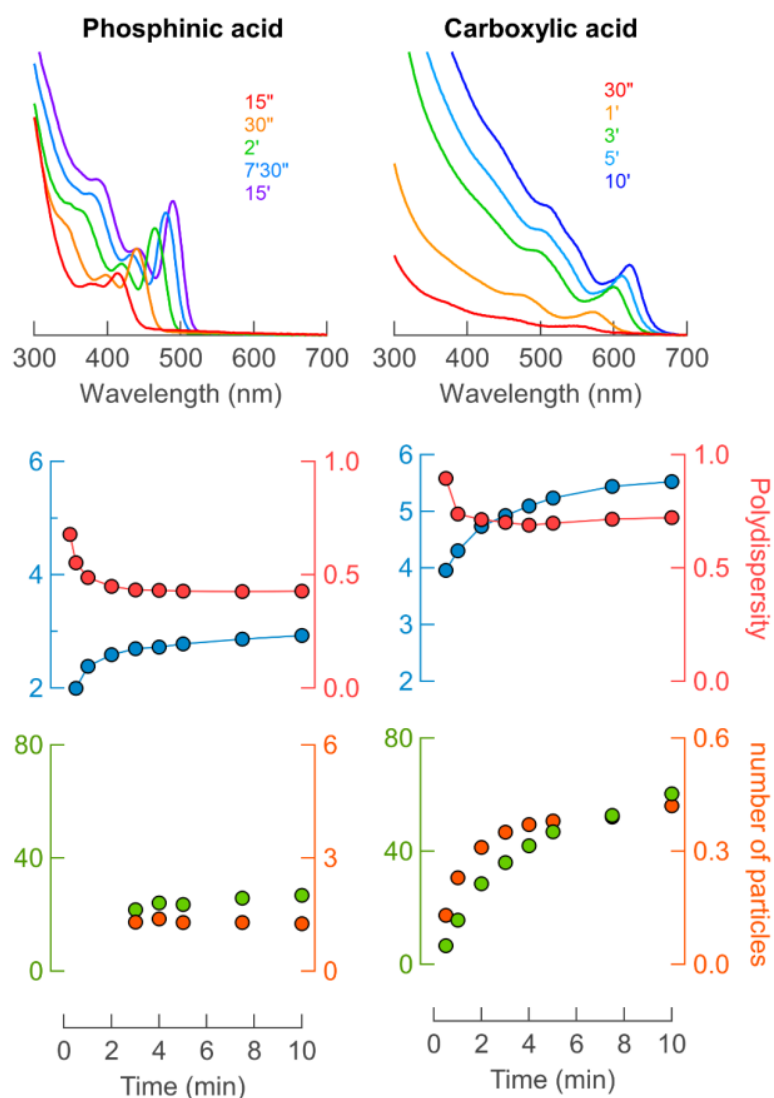

Figure 2. UV-Vis absorption spectra of CdSe quantum dots synthesized with phosphonic acid at $300^{\circ} \mathrm{C}$, with phosphinic acid at $300{ }^{\circ} \mathrm{C}$, with phosphinic acid at $240{ }^{\circ} \mathrm{C}$, and with carboxylic acid at $240{ }^{\circ} \mathrm{C}$. Also the extracted mean diameter, the polydispersity (represented by the valley-to-peak ratio), the reaction yield and the number of particles are plotted for the four different reactions.

With phosphinic acids we did not observe an induction time. At $300{ }^{\circ} \mathrm{C}$, particles are formed almost instantaneously and the first particles are also much smaller $(2.5 \mathrm{~nm})$ than the first particles observed for phosphonic acids $(3.4 \mathrm{~nm})$. The reaction reaches also a higher yield after 10 min (72\% vs $28 \%$ for phosphinic and phosphonic acids respectively). Most of the reaction with phosphinic acids is already completed after $2 \mathrm{~min}$. However, the particles continue to grow, presumably through a ripening mechanism since the number of particles slightly decreases and the polydispersity significantly increases (Figure 2). Clearly, phosphinic acids allow for a higher reactivity than phosphonic acids (faster yield development and lower barrier 
for nucleation). Furthermore, the formed particles with phosphinic acids are particularly small ( $<3 \mathrm{~nm}$, a size range that is usually difficult to access) and the particles have very sharp first excitonic features (FWHM at $2.7 \mathrm{eV}: 260 \mathrm{meV}$ ). An additional advantage of the phosphinic acids for kinetic analysis is the long term stability of the dispersions. While kinetic analysis has to be performed immediately for the phosphonic acids samples due to partial gelation (causing scattering in UV-Vis) the phosphinic acid samples give identical results after 20 weeks, see Figure S5.

At $240{ }^{\circ} \mathrm{C}$ (Figure 2), the yield development seems more sluggish for phosphinic acids compared to carboxylic acids, suggesting that phosphinic acids are less reactive than carboxylic acids. Note that we could not determine the yield (and thus the particle number) for the aliquots taken until 2 min since the absorption at $340 \mathrm{~nm}$ is not size independent for these very small sizes $(<2.7 \mathrm{~nm})$. While for carboxylic acids, we see again continuous nucleation (increasing particle number as the yield increases, see Figure 2), we do not observe such a feature for the phosphinic acids. The particle number remains constant while the yield increases slightly. We do not observe ripening for the phosphinic acids at $240^{\circ} \mathrm{C}$. Instead, the size dispersion focuses while the particles are growing. Again, very small particles $(2-3 \mathrm{~nm})$ are obtained with sharp excitonic features (FWHM at $2.54 \mathrm{eV}: 244 \mathrm{meV}$ ). We conclude that the phosphinic acid ligands lead to particle ensembles with more narrow size dispersions and that their reactivity is intermediate between phosphonic and carboxylic acids.

Photoluminescence properties. In our hands, we obtained a photoluminescence quantum yield (PLQY) of $5.6 \%$ for crude, i.e., unpurified reaction mixture, CdSe synthesized with oleic acid at $240{ }^{\circ} \mathrm{C}$ (Figure S6D). After purification, this decreased to $0.5 \%$. For the CdSe particles synthesized with phosphonic acids, we obtained a very low PLQY of $0.2 \%$ for the crude and < $0.1 \%$ after purifications (Figure S6A). CdSe synthesized with phosphinic acid under identical conditions at $300{ }^{\circ} \mathrm{C}$, we obtained a PLQY of $18 \%$ for the crude aliquot at 10 seconds (first 
excitonic peak at $2.7 \mathrm{eV}$ ), with a FHWM of $150 \mathrm{meV}$ (Figure S6B). After ripening, the PLQY decreases to $15 \%$ and after purification we measure only $3 \%$. For CdSe synthesized with phosphinic acid at $240{ }^{\circ} \mathrm{C}$, we measure a PLQY of $11 \%$ for the crude after 15 min reaction (first excitonic peak at $2.53 \mathrm{eV}$ ) and the FWHM was $130 \mathrm{meV}$ (Figure S6C). After purification, the PLQY reduced to 4\%. A full photophysical analysis is outside the scope of this work, and there are higher quantum yields reported for the phosphonic acid based CdSe quantum dots in the literature. However, it is clear that, in our hands and under identical conditions, CdSe nanocrystal synthesized with phosphinic acids have a significantly higher PLQY with values up to par with the state of the art of unshelled CdSe nanocrystals, and with very narrow linewidths.

Synthesis of CdSe and CdS nanorods. Phosphonic acids are also used in reactions to obtain anisotropic nanocrystals, such as nanorods. Buhro et al. synthesized CdSe nanorods by reacting cadmium tetradecylphosphonate with TOP-Se in the presence of di-n-octylphosphinic acid (DOPA). ${ }^{32}$ The TOP-Se is injected at $275^{\circ} \mathrm{C}$ but the temperature is allowed to drop to $250{ }^{\circ} \mathrm{C}$ during the growth of the rods. The amount of added DOPA controls the aspect ratio. We successfully reproduced this method but we obtained, apart from the intended rods, also tetrapods (Figure 3 and S7). When we perform the same reaction with cadmium tetradecylphosphinate, no rods but regular quantum dots are obtained (Figure S8). The reaction reaches maximum yield at $1 \mathrm{~min}$, after which the particles start ripening. We attribute this result to the higher reactivity of cadmium phosphinate, depleting all the precursor already during the formation of the seeds. Therefore, we lowered also the injection temperature to $250{ }^{\circ} \mathrm{C}$, and particles with a slightly anisotropic shape are obtained (Figure S9). Decreasing the temperature even further (TOP-Se is injected at $250{ }^{\circ} \mathrm{C}$ and the temperature is allowed to drop to $225^{\circ} \mathrm{C}$ for 
the growth), results in nanorods (Figure 3 and S10) albeit with a small aspect ratio and some tetrapods are again observed.

TOP-S has a higher phosphor-chalcogen bond dissociation energy (BDE) than TOP-Se. ${ }^{18} \mathrm{We}$ thus hypothesized that cadmium phosphinate would be more suitable to grown $\mathrm{CdS}$ rods since the higher BDE of TOP-S would decrease the precursor conversion rate. Gratifyingly, CdS rods were indeed obtained when TOP-S was injected at $275^{\circ} \mathrm{C}$ and the rods were grown at $250^{\circ} \mathrm{C}$ (Figure 3). The nanorods were highly monodisperse (width: $2.4 \pm 0.3 \mathrm{~nm}$, and length: $14.6 \pm$ $2.8 \mathrm{~nm}$ ) and the sample had $>99 \%$ shape purity (Figure S11). In comparison, the control experiment with phosphonic acid failed several times. In one case the reaction resulted in $\mathrm{CdS}$ rods but they were contaminated with tetrapods. Furthermore, the rods with phosphinic acid were easier to purify due to the absence of phosphonic acid anhydride gel.

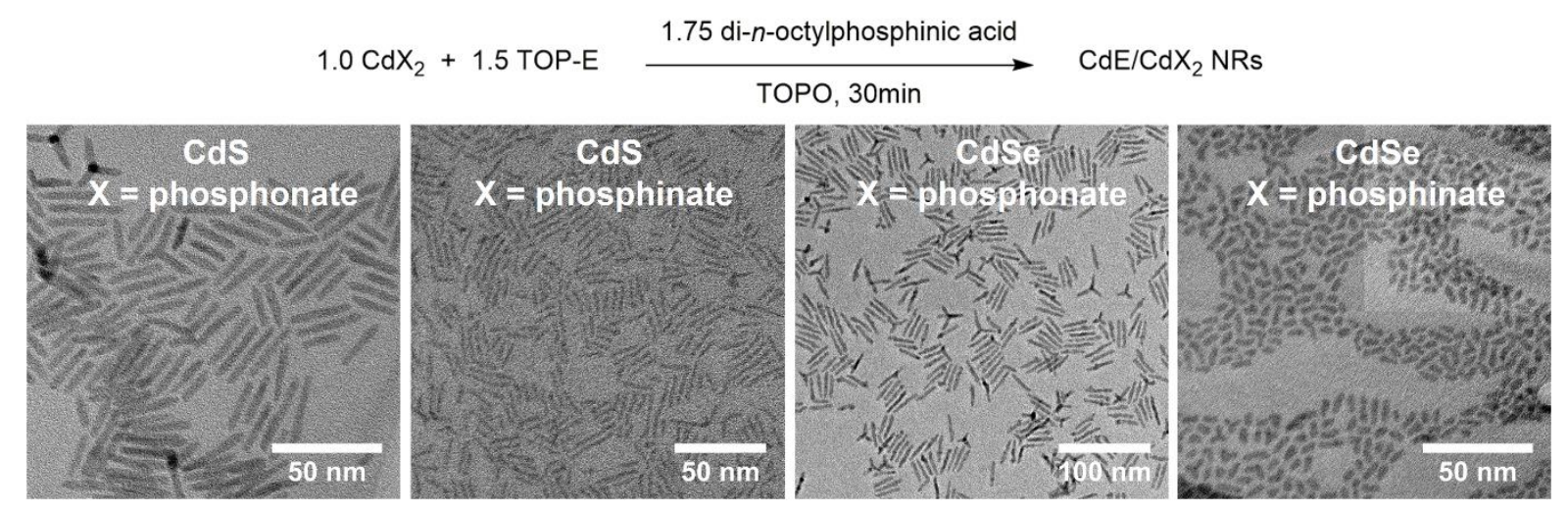

Figure 3. CdS and CdSe nanorods synthesized with phosphonic and phosphinic acid.

\section{Conclusion}

We have presented convenient strategies to synthesize phosphinic acids that are relevant for nanocrystals synthesis. Furthermore, cadmium phosphinate was shown to react with TOP-Se to form CdSe nanocrystals of high purity, low polydispersity and high photoluminescence quantum yield. We also demonstrated the synthesis of CdSe and CdS nanorods with high shape 
uniformity for the latter. Compared to nanocrystals synthesized with phosphonic acids, the ones synthesized with phosphinic acids are more easily purified since no phosphonic acid anhydride gel is formed. Interestingly, the reactivity of cadmium phosphinate is intermediate between cadmium phosphonate and cadmium carboxylate. This provides researchers with an additional handle on the kinetics of precursor conversion, which seems so far dominated by tuning the chalcogen precursors. In addition, we did not find any indication of continuous nucleation in the case of cadmium phosphinate. While this points to interesting mechanistic differences, more detailed studies are necessary to uncover its wider implications.

\section{Experimental}

General considerations. All manipulations are performed in air, unless otherwise indicated. All chemicals are used as received unless otherwise mentioned. 1-Hexene (99\%), hypophosphorous acid (50\% aqueous solution), lithium aluminium hydride (95\%), potassium hydrogen sulfate (99\%), and triethylborane (1M in THF) were purchased from Acros. 1Tetradecene (94\%), cadmium oxide (99.998\%), calcium hydride (92\%), benzene $(99.5 \%)$, magnesium turnings (99.9\%), magnesium sulfate (99.0\%), sulfur (99.5\%), and chloroform-d1 (99.8\%D stabilized with Ag) were purchased from Carl Roth. Acetone (99\%), acetonitrile (99.9\%), celite, chloroform (99.5\%), dichloromethane (99.8\%), diethyl ether (99.5\%), dioxane (99.9\%), ethanol absolute (99.9\%), ethyl acetate (99.5\%), $n$-heptane (99\%), $n$-hexane (99\%), hydrochloric acid (37\%), methanol (99\%), silica gel 60A (40-63 $\mu \mathrm{m})$, sodium chloride $(99.8 \%)$, sodium hydroxide $(98.5 \%)$, sodium sulfate $(99 \%)$, tetrahydrofuran $(99.9 \%)$, toluene $(99.9 \%)$, and trifluoroacetic acid (99\%) were purchased from Chem-Lab. n-Hexylphosphonic acid (97\%), n-tetradecylphosphonic acid (97\%), and n-octadecylphosphonic acid (97\%) were purchased from PlasmaChem. 1,2-Dibromoethane (98\%), 1-bromooctadecane (97\%), 1octadecene (90\%), 1-octene (98\%), 2-ethyl-hexylbromide (95\%), benzoylperoxide (moistened 
with $25 \%$ water), bromotrimethylsilane (97\%), diethyl chlorophosphite (95\%), methanesulfonyl chloride (99.7\%), oleic acid (90\%), potassium carbonate (99\%), potassium hydroxide (90\%), potassium tert-butoxide (98\%), sodium hypophosphite monohydrate (99\%) tetrabromomethane (99\%), trimethylamine (99\%), and triphenylphosphine (99\%) were purchased from Sigma-Aldrich. Selenium (99.99\%), tri- $n$-octylphosphine (90\%), and tri- $n$ octylphosphine oxide (90\%) were purchased from STREM. Trifluoroacetic anhydride was purchased from TCI. Benzene- $\mathrm{d}_{6}(99.5 \% \mathrm{D})$, methanol- $d_{4}(99.8 \% \mathrm{D})$, and toluene- $\mathrm{d}_{8}(99.5 \% \mathrm{D})$ were purchased from VWR.

When required, organic solvents are dried according to the procedure described by Williams et $a l .{ }^{55}$ making use of $20 \% \mathrm{~m} / \mathrm{v}$ freshly activated $3 \AA$ sieves for minimum 120 hours.

Trioctylphosphine oxide (TOPO) is recrystallized on a scale of $200 \mathrm{~g}$ by the following procedure described by Owen al. to obtain purified white needles (178 g, 89\%). ${ }^{26,33}$ Sulfur is recrystallized on a scale of $12.5 \mathrm{~g}$ by the following procedure. Sulfur is dissolved in toluene (1 $\mathrm{mg} / \mathrm{mL}$ ) at $100{ }^{\circ} \mathrm{C}$ and filtered over a hot frit. While the solution is cooling down to room temperature, shiny yellow needles grow. Afterwards, these needles are filtered and extensively vacuum dried $(9.0 \mathrm{~g}, 72 \%)$. $n$-Octadecylphosphonic acid is synthesized according to the procedure described by De Roo et al. ${ }^{23}$ on a $75 \mathrm{mmmol} n$-octadecyl bromide scale $(18.9 \mathrm{~g}, 76$ \%). Di- $n$-octylphosphinic acid is synthesized according to the procedure described by Buhro $e t$ $a .^{33}$ on a $200 \mathrm{mmol}$ hypophosphorous acid scale (17.2 g, $\left.30 \%\right)$.

Synthesis of mono-alkylphosphinic acid. Mono-alkylphosphinic acids are synthesized according to the procedure of Montchamp et al. with slight adaptations. ${ }^{41}$ An open $250 \mathrm{~mL}$ flask is loaded with sodium hypophosphite hydrate (6.63 g, $62.5 \mathrm{mmol}, 2.5$ eq.), 1-alkene (25 mmol, 1.0 eq.), methanol (125 mL), and $1 \mathrm{~mol} \mathrm{~L}^{-1}$ triethylborane in tetrahydrofuran $(25 \mathrm{~mL}, 25$ mmol, 1.0 eq.) which is vigorously stirred for 3 hours open to the air. Afterwards, the reaction 
mixture is transferred to a separating funnel $(1 \mathrm{~L})$ to which dichloromethane $(125 \mathrm{~mL})$ and 1 mol L${ }^{-1}$ solution of $\mathrm{KHSO}_{4}(125 \mathrm{~mL})$ is added. The aqueous phase is washed once again with dichloromethane $(125 \mathrm{~mL})$. All the organic phases are collected, dried with $\mathrm{Na}_{2} \mathrm{SO}_{4}$, and concentrated on the rotary evaporator. For solid products, such as $n$-octadecyl- and $n$ tetradecylphosphinic acid, a recrystallization from hot $n$-hexane $(25 \mathrm{~mL})$ is performed twice to obtain a final purified white product. For liquid products, such as $n$-hexylphosphinic acid, the product is first transformed to its potassium salt by adding a stoichiometric amount of potassium hydroxide in EtOH $\left(0.5 \mathrm{~mol} \mathrm{~L}^{-1}\right)$. After 1 hour stirring, the salt is concentrated on the rotary evaporator and twice recrystallized from a hot mixture of $n$-hexane $(10 \mathrm{~mL})$, tetrahydrofuran $(10 \mathrm{~mL})$, and ethanol $(1 \mathrm{~mL})$.

n-Octadecylphosphinic acid (5.1 g, $61.0 \%) .{ }^{1} \mathbf{H}$ NMR $\left(300 \mathrm{MHz}, \mathrm{CDCl}_{3}\right): \delta 8.70(\mathrm{~s}, 1 \mathrm{H}), 8.00$ $(\mathrm{t}, J=1.8 \mathrm{~Hz}, 0.5 \mathrm{H}), 6.20(\mathrm{t}, J=1.8 \mathrm{~Hz}, 0.5 \mathrm{H}), 1.75$ (quin, $J=8.5 \mathrm{~Hz}, 2 \mathrm{H}), 1.65-1.45(\mathrm{~m}, 2 \mathrm{H})$, 1.45-0.95 (m, 30H), $0.85(\mathrm{t}, J=7.0 \mathrm{~Hz}, 3 \mathrm{H}) .{ }^{13} \mathbf{C} \mathbf{N M R}\left(75 \mathrm{MHz}, \mathrm{CDCl}_{3}\right): \delta 32.10,30.67,30.50$, 30.24, 29.87, 29.75, 29.53, 29.30, 28.99, 22.85, 20.62, 14.28. ${ }^{31} \mathbf{P}[\mathbf{1 H}] \mathbf{N M R}\left(75 \mathrm{MHz}, \mathrm{CDCl}_{3}\right)$ : $\delta 40.14$ ppm. LC-MS (API-ES) calc for $\mathrm{C}_{18} \mathrm{H}_{38} \mathrm{O}_{2} \mathrm{P}[\mathrm{M}-\mathrm{H}]^{-}$317.26, found 317.2.

n-Tetradecylphosphinic acid (3.2 g, $48.1 \%) .{ }^{1} \mathbf{H} \mathbf{N M R}\left(300 \mathrm{MHz}, \mathrm{CDCl}_{3}\right): \delta 9.45(\mathrm{~s}, 1 \mathrm{H}), 8.00$ (t, $J=1.8 \mathrm{~Hz}, 0.5 \mathrm{H}), 6.20(\mathrm{t}, J=1.8 \mathrm{~Hz}, 0.5 \mathrm{H}), 1.75$ (quin, $J=8.5 \mathrm{~Hz}, 2 \mathrm{H}), 1.60-1.35(\mathrm{~m}, 2 \mathrm{H})$, 1.35-0.95 (m, 22H), $0.85(\mathrm{t}, J=7.0 \mathrm{~Hz}, 3 \mathrm{H}) .{ }^{13} \mathbf{C} \mathbf{N M R}\left(75 \mathrm{MHz}, \mathrm{CDCl}_{3}\right): \delta 31.92,30.52,30.31$, 30.02, 29.69, 29.66, 29.63, 29.59, 29.36, 29.13, 28.78, 22.69, 20.45, 14.11. ${ }^{31} \mathbf{P}[\mathbf{1 H}] \mathbf{N M R}$ (75MHz, $\left.\mathrm{CDCl}_{3}\right): \delta 39.6$ ppm. LC-MS (API-ES) calc for $\mathrm{C}_{14} \mathrm{H}_{32} \mathrm{O}_{2} \mathrm{P}[\mathrm{M}+\mathrm{H}]^{+}$263.21, found 263.2.

Potassium n-hexylphosphinate (3.0 g, $63.2 \%) .{ }^{1} \mathbf{H}$ NMR $\left(300 \mathrm{MHz}, \mathrm{MeOD}-\mathrm{d}_{4}\right): \delta 7.78(\mathrm{t}, J=$ $1.6 \mathrm{~Hz}, 0.5 \mathrm{H}), 6.16(\mathrm{t}, J=1.6 \mathrm{~Hz}, 0.5 \mathrm{H}), 1.65-1.05(\mathrm{~m}, 10 \mathrm{H}), 0.91(\mathrm{t}, J=6.9 \mathrm{~Hz}, 3 \mathrm{H}) .{ }^{13} \mathrm{C} \mathrm{NMR}$ 
$\left(75 \mathrm{MHz}, \mathrm{MeOD}-\mathrm{d}_{4}\right): \delta 34.37,32.75,31.79,23.59,23.05,14.42 .{ }^{31} \mathbf{P}[\mathbf{1 H}] \mathbf{N M R}(75 \mathrm{MHz}$, MeOD-d4): $\delta 27.8$ ppm. LC-MS (API-ES) calc for $\mathrm{C}_{6} \mathrm{H}_{10} \mathrm{O}_{2} \mathrm{PK}[\mathrm{M}-\mathrm{K}]^{-}$149.07, found 149.2.

n-Hexylphosphinic acid (1.6 g, $42.0 \%) .{ }^{1} \mathbf{H}$ NMR (300MHz, $\left.\mathrm{CDCl}_{3}\right): \delta 9.45$ (s, $\left.1 \mathrm{H}\right), 8.00(\mathrm{t}, J$ $=1.8 \mathrm{~Hz}, 0.5 \mathrm{H}), 6.20(\mathrm{t}, J=1.8 \mathrm{~Hz}, 0.5 \mathrm{H}), 1.75($ quin, $J=8.5 \mathrm{~Hz}, 2 \mathrm{H}), 1.65-1.45(\mathrm{~m}, 2 \mathrm{H}), 1.35-$ $0.95(\mathrm{~m}, 6 \mathrm{H}), 0.85(\mathrm{t}, J=7.0 \mathrm{~Hz}, 3 \mathrm{H}) .{ }^{13} \mathrm{C} \mathbf{N M R}\left(75 \mathrm{MHz}, \mathrm{CDCl}_{3}\right): \delta .31 .40,30.07,28.64$, 22.48, 20.67, 14.09. ${ }^{31} \mathbf{P}[\mathbf{1 H}]$ NMR $\left(75 \mathrm{MHz}, \mathrm{CDCl}_{3}\right): \delta 38.7$ ppm. LC-MS (API-ES) calc for $\mathrm{C}_{6} \mathrm{H}_{16} \mathrm{O}_{2} \mathrm{P}[\mathrm{M}+\mathrm{H}]^{+}$151.09, found 151.1.

Synthesis of $(\boldsymbol{Z})$-octadec-9-en-1-ol (oleyl alcohol). Oleyl alcohol is synthesized by reducing oleic acid according to the procedure published by Grela et al. ${ }^{43}$ In a $1 \mathrm{~L}$ flask, $\mathrm{LiAlH}_{4}(10 \mathrm{~g}$, $260 \mathrm{mmol}, 3.5$ eq.) is added, degassed three times, and put under argon. After the addition of dry THF $(300 \mathrm{~mL})$, the flask is cooled to $0{ }^{\circ} \mathrm{C}$ in an ice bath. Dried oleic acid $(21.48 \mathrm{~g}, 24.0$ $\mathrm{mL}, 76 \mathrm{mmol}, 1.0$ eq.) is added dropwise. The reaction is allowed to heat up to room temperature and stirred for 4 hours. Afterwards, the reaction flask is again cooled to $0{ }^{\circ} \mathrm{C}$ just before diethyl ether $(400 \mathrm{~mL}), \mathrm{H}_{2} \mathrm{O}(10 \mathrm{~mL}), 15 \% \mathrm{NaOH}$ solution $(10 \mathrm{~mL})$, and $\mathrm{H}_{2} \mathrm{O}(32 \mathrm{~mL})$ is carefully added. After 15 minutes of additional stirring, the reaction mixture is dried using $\mathrm{MgSO}_{4}$, and filtered over celite. The filtrate is first vacuum dried, and then vacuum distilled following the same vacuum distillation procedure as described above to obtain a colourless viscous liquid (17.5 g, $86 \%) .{ }^{1} \mathbf{H}$ NMR $\left(400 \mathrm{MHz}, \mathrm{CDCl}_{3}\right): \delta 5.40-5.25(\mathrm{~m}, 2 \mathrm{H}), 3.60(\mathrm{t}, J=$ $6.6 \mathrm{~Hz}, 2 \mathrm{H}), 2.05-1.90(\mathrm{~m}, 4 \mathrm{H}), 1.55$ (quin, $J=7.0 \mathrm{~Hz}, 2 \mathrm{H}), 1.45(\mathrm{~s}, 1 \mathrm{H}), 1.40-1.10(\mathrm{~m}, 22 \mathrm{H})$, $0.85(\mathrm{t}, J=7.1 \mathrm{~Hz}, 3 \mathrm{H}) .{ }^{13} \mathbf{C} \mathbf{N M R}\left(75 \mathrm{MHz}, \mathrm{CDCl}_{3}\right): \delta 130.09,129.94,63.18,32.93,32.04$, 29.90, 29.88, 29.66, 29.64, 29.55, 29.46, 29.37, 27.35, 27.33, 25.88, 22.82, 14.24. LC-MS (API-ES) calc for $\mathrm{C}_{18} \mathrm{H}_{37} \mathrm{O}[\mathrm{M}+\mathrm{H}]^{+} 269.28$, found 269.3.

Synthesis of (Z)-octadec-9-en-1-yl methane sulfonate (oleyl mesylate). In a $250 \mathrm{~mL}$ Schlenk flask, oleyl alcohol (13.42 g, $15.51 \mathrm{~mL}, 50 \mathrm{mmol}, 1.0 \mathrm{eq}$.) is added, degassed three times, and 
put under argon. After the addition of dry dichloromethane $(100 \mathrm{~mL})$ and dried triethylamine (5.57 g, $7.67 \mathrm{~mL}, 55 \mathrm{mmol}, 1.1 \mathrm{eq}$.$) , the flask is cooled to 0{ }^{\circ} \mathrm{C}$ in an ice bath. Dry mesylate chloride $(6.30 \mathrm{~g}, 4.26 \mathrm{~mL}, 55 \mathrm{mmol}, 1.1$ eq.) is added dropwise and further stirred for 30 minutes, followed by the addition of $\mathrm{H}_{2} \mathrm{O}(50 \mathrm{~mL})$. After 30 minutes of additional stirring, the reaction mixture is transferred to a separation funnel $(300 \mathrm{~mL})$ where the organic phase is kept and the aqueous phase is extracted twice with chloroform $(50 \mathrm{~mL})$. All the organic phases are collected together and washed with: (1) a mixture of $25 \% \mathrm{~K}_{2} \mathrm{CO}_{3}$ solution $(25 \mathrm{~mL})$ and $\mathrm{H}_{2} \mathrm{O}$ (50 mL); (2) brine (50 mL), and dried with $\mathrm{MgSO}_{4}$. After vacuum drying, a colourless viscous liquid is obtained (17.2 g, $99 \%) .{ }^{1} \mathbf{H}$ NMR $\left(300 \mathrm{MHz}, \mathrm{CDCl}_{3}\right): \delta 5.40-5.25(\mathrm{~m}, 2 \mathrm{H}), 4.20(\mathrm{t}, J$ $=6.6 \mathrm{~Hz}, 2 \mathrm{H}), 2.95(\mathrm{~s}, 3 \mathrm{H}), 2.10-1.95(\mathrm{~m}, 4 \mathrm{H}), 1.70$ (quin, $J=7.5 \mathrm{~Hz}, 2 \mathrm{H}), 1.50-1.10(\mathrm{~m}, 22 \mathrm{H})$, $0.85(\mathrm{t}, J=7.2 \mathrm{~Hz}, 3 \mathrm{H}) .{ }^{13} \mathbf{C} \mathbf{N M R}\left(75 \mathrm{MHz}, \mathrm{CDCl}_{3}\right): \delta 130.18,129.86,70.30,37.51,32.05$, 29.90, 29.83, 29.66, 29.46, 29.28, 29.15, 27.36, 27.30, 25.56, 22.82, 14.25. LC-MS (API-ES) calc for $\mathrm{C}_{19} \mathrm{H}_{42} \mathrm{NO}_{3} \mathrm{~S}\left[\mathrm{M}+\mathrm{NH}_{4}\right]^{+} 364.29$, found 364.3.

Synthesis of (Z)-octadec-9-en-1-yl bromide (oleyl bromide). Oleyl bromide is synthesized according to the procedure of De Roo et al. with slight adaptations. ${ }^{23}$ A $250 \mathrm{~mL}$ flask is loaded with oleyl alcohol (13.42 g, $15.81 \mathrm{~mL}, 50 \mathrm{mmol}, 1.0$ eq.), tetrabromomethane (18.24 g, 55 mmol, 1.1 eq. $)$, and dry dichloromethane $(50 \mathrm{~mL})$, and cooled to $0{ }^{\circ} \mathrm{C}$ with an ice bath. Triphenylphsophine (15.74 g, $60 \mathrm{mmol}, 1.2$ eq.) was added in portions over 15 minutes. The reaction was allowed to stir for 1 hour at room temperature. Afterwards, hexanes $(50 \mathrm{~mL})$ is added to the mixture, cooled in the freezer to precipitate triphenylphosphine oxide, filtered over a silica plug, and the filtrate is evaporated. This step is repeated a second time to remove all the triphenylphosphine oxide, resulting in a colourless liquid $(16.3 \mathrm{~g}, 98 \%)$ which is vacuum dried overnight to remove bromoform, and stored in fridge. ${ }^{1} \mathbf{H}$ NMR $\left(300 \mathrm{MHz}, \mathrm{CDCl}_{3}\right): \delta 5.40-5.25$ (m, 2H), $3.40(\mathrm{t}, J=6.9 \mathrm{~Hz}, 2 \mathrm{H}), 2.10-1.90(\mathrm{~m}, 4 \mathrm{H}), 1.85$ (quin, $J=7.7 \mathrm{~Hz}, 2 \mathrm{H}), 1.50-1.10$ (m, 22H), $0.85(\mathrm{t}, J=7.0 \mathrm{~Hz}, 3 \mathrm{H}) .{ }^{13} \mathrm{C} \mathbf{N M R}\left(75 \mathrm{MHz}, \mathrm{CDCl}_{3}\right): \delta 130.16,129.91,34.13,33.01$, 
$32.07,29.94,29.88,29.70,29.49,29.35,28.92,28.35,27.40,27.33,22.86,14.28$. GC-MS molecular mass for $\mathrm{C}_{18} \mathrm{H}_{35} \mathrm{Br}$ [M] 331.38, found 331 (average mass).

Synthesis of (Z)-octadeca-1,9-diene. A $500 \mathrm{~mL}$ flask is loaded with oleyl bromide $(16.57 \mathrm{~g}$, 50 mmol, 1.0 eq.), evacuated, and set under argon atmosphere. Dry tetrahydrofuran $(200 \mathrm{~mL})$ is added and cooled down to $0{ }^{\circ} \mathrm{C}$ with an ice bath. Potassium tert-butoxide (1M in THF, 115 $\mathrm{mL}, 115 \mathrm{mmol}, 2.3$ eq.) is added dropwise. It is important that a full yield is obtained since separation between the diene and bromide is not straightforward. The reaction mixture is allowed to warm to room temperature after the addition of the first equivalent of base and stirred overnight. Afterwards, chloroform $(200 \mathrm{~mL})$ is added, and the mixture is washed twice with water $(200 \mathrm{~mL})$ which is discarded. The organic phase is evaporated, and vacuum distilled over $\mathrm{CaH}_{2}$ to result in a colourless liquid $(9.4 \mathrm{~g}, 75 \%) .{ }^{1} \mathbf{H}$ NMR $\left(400 \mathrm{MHz}, \mathrm{CDCl}_{3}\right): \delta 5.90-5.70(\mathrm{~m}$, $1 \mathrm{H}), 5.40-5.25(\mathrm{~m}, 2 \mathrm{H}), 5.05-4.85(\mathrm{~m}, 2 \mathrm{H}), 2.10-1.90(\mathrm{~m}, 6 \mathrm{H}), 1.50-1.15(\mathrm{~m}, 20 \mathrm{H}), 0.85(\mathrm{t}, J=$ 7.1 Hz, 3H). ${ }^{13} \mathbf{C ~ N M R}\left(75 \mathrm{MHz}, \mathrm{CDCl}_{3}\right): \delta 139.34,130.12,129.95,114.29,33.97,32.08,29.95$, 29.89, 29.70, 29.50, 29.32, 29.20, 29.08, 27.40, 27.36, 22.87, 14.26. GC-MS molecular mass for $\mathrm{C}_{18} \mathrm{H}_{34}[\mathrm{M}] 250.47$, found 250 (average mass).

Synthesis of ethyl (2-ethyl-hexyl)phosphinate ester is synthesized according to the procedure of Meier et al. ${ }^{46}$ with slight adaptations. In an argon filled glovebox, a $250 \mathrm{~mL}$ Schlenk flask is loaded with diethyl chlorophosphite $(3913.8 \mathrm{mg}, 3.595 \mathrm{~mL}, 25 \mathrm{mmol}, 1.00$ eq.) and dry tetrahydrofuran $(50 \mathrm{~mL})$. The flask is transferred to the Schlenk line and cooled down to $0{ }^{\circ} \mathrm{C}$ in an ice bath. Separately, an oven dried $100 \mathrm{~mL}$ Schlenk flask is loaded with activated (sanded) magnesium turnings (1.3 g, $52.5 \mathrm{mmol}, 2.15$ eq.), dry tetrahydrofuran (50 mL), 2-ethylhexylbromide (3478.0 mg, $3.205 \mathrm{~mL}, 25 \mathrm{mmol}, 1.00$ eq.), a few drops of dry 1,2dibromoethane, and is stirred at room temperature overnight prior to a filtered Cannula transfer into the first solution. After the addition, the reaction mixture is stirred overnight at $50{ }^{\circ} \mathrm{C}$. The next day, the solvent is evaporated, concentrated hydrochloric acid $(5 \mathrm{~mL})$ and water $(75 \mathrm{~mL})$ 
is added and stirred for 2 hours at room temperature. Afterwards, the reaction mixture is extracted twice with dichloromethane $(75 \mathrm{~mL})$, dried with $\mathrm{Na}_{2} \mathrm{SO}_{4}$, concentrated on the rotary evaporator, and purified using silica gel column chromatography (EtOAc). The final product is vacuum dried overnight to remove all solvent traces and result in a colourless liquid $(2.5 \mathrm{~g}, 49$ \%). ${ }^{1} \mathrm{H}$ NMR (400MHz, $\left.\mathrm{CDCl}_{3}\right): \delta 7.75(\mathrm{t}, J=1.9 \mathrm{~Hz}, 0.5 \mathrm{H}), 6.45(\mathrm{t}, J=2.1 \mathrm{~Hz}, 0.5 \mathrm{H}), 4.20-$ $3.95(\mathrm{~m}, 2 \mathrm{H}), 1.85-1.65(\mathrm{~m}, 3 \mathrm{H}), 1.50-1.10(\mathrm{~m}, 11 \mathrm{H}), 0.90-0.75(\mathrm{~m}, 6 \mathrm{H}) .{ }^{13} \mathbf{C}$ NMR $(100 \mathrm{MHz}$, $\left.\mathrm{CDCl}_{3}\right): \delta 62.40,33.89,33.54,32.65,28.57,27.14,22.90,16.34,14.11,10.57 .{ }^{31} \mathbf{P}[\mathbf{1 H}] \mathbf{N M R}$ $\left(160 \mathrm{MHz}, \mathrm{CDCl}_{3}\right): \delta 38.53$ ppm. LC-MS (API-ES) calc for $\mathrm{C}_{10} \mathrm{H}_{24} \mathrm{O}_{2} \mathrm{P}[\mathrm{M}+\mathrm{H}]^{+} 207.15$, found 207.2.

Synthesis of ethyl (oleyl)phosphinate ester is synthesized using the same procedure as for ethyl (2-ethyl-hexyl)phosphinate ester but with oleyl bromide ( $8284.3 \mathrm{mg}, 25 \mathrm{mmol}, 1.00 \mathrm{eq}$. instead of 2-ethyl-hexylbromide. The final product is a colourless liquid (1.6 g, 18.6 \%). ${ }^{\mathbf{1}} \mathbf{H}$ NMR (400MHz, $\left.\mathrm{CDCl}_{3}\right): \delta 7.70(\mathrm{t}, J=1.8 \mathrm{~Hz}, 0.5 \mathrm{H}), 6.40(\mathrm{t}, J=1.9 \mathrm{~Hz}, 0.5 \mathrm{H}), 5.40-5.25(\mathrm{~m}$, 2H), 4.25-3.95 (m, 2H), 2.10-1.85 (m, 4H), 1.80-1.65 (m, 2H), 1.65-1.50 (m, 2H), 1.50-1.15 $(\mathrm{m}, 25 \mathrm{H}), 0.85(\mathrm{t}, J=6.8 \mathrm{~Hz}, 3 \mathrm{H}) .{ }^{13} \mathbf{C} \mathbf{N M R}\left(100 \mathrm{MHz}, \mathrm{CDCl}_{3}\right): \delta 130.12,129.84,62.38,32.02$, $30.63,30.48,29.89,29.80,29.65,29.44,29.37,29.31,29.24,28.42,27.37,27.28,22.79,20.84$, 16.40, 14.22. ${ }^{31} \mathbf{P}[\mathbf{1 H}]$ NMR $\left(160 \mathrm{MHz}, \mathrm{CDCl}_{3}\right): \delta 38.94 \mathrm{ppm}$. LC-MS (API-ES) calc for $\mathrm{C}_{20} \mathrm{H}_{42} \mathrm{O}_{2} \mathrm{P}[\mathrm{M}+\mathrm{H}]^{+}$345.29, found 345.3.

Synthesis of 2-ethyl-hexyl and oleylphosphinic acid. The phosphinate is dissolved in dry dichloromethane (2 $\mathrm{mL}$ per gram phosphinate) in dried Schlenk flask. TMS-Br (1.15 equivalents) is added and the reaction mixture is stirred overnight under argon. The volatiles are removed by evaporation, excess dry methanol ( $5 \mathrm{~mL}$ per gram phosphinate) is added and the solution is stirred for 6 hours at $40{ }^{\circ} \mathrm{C}$. Afterwards, the solvent is removed by evaporation and the product is vacuum dried overnight at $50{ }^{\circ} \mathrm{C}$ to remove methanol. 
(2-Ethylhexyl)phosphinic acid, quantitative yield. ${ }^{\mathbf{1}} \mathbf{H} \mathbf{~ N M R}\left(400 \mathrm{MHz}, \mathrm{CDCl}_{3}\right): \delta 11.50(\mathrm{~s}, 1 \mathrm{H})$ $7.85(\mathrm{~s}, 0.5 \mathrm{H}), 6.50(\mathrm{~s}, 0.5 \mathrm{H}), 1.90-1.65(\mathrm{~m}, 3 \mathrm{H}), 1.55-1.10(\mathrm{~m}, 8 \mathrm{H}), 0.95-0.75(\mathrm{~m}, 6 \mathrm{H}) .{ }^{13} \mathrm{C}$ NMR $\left(100 \mathrm{MHz}, \mathrm{CDCl}_{3}\right): \delta 33.90,33.81,33.36,28.53,27.10,22.93,14.16,10.52 .{ }^{31} \mathbf{P}[\mathbf{1 H}]$ NMR (160MHz, $\left.\mathrm{CDCl}_{3}\right): \delta 38.29$ ppm. LC-MS (API-ES) calc for $\mathrm{C}_{8} \mathrm{H}_{20} \mathrm{O}_{2} \mathrm{P}[\mathrm{M}+\mathrm{H}]^{+} 179.12$, found 179.2 .

Oleylphosphinic acid, quantitative yield. ${ }^{1} \mathbf{H}$ NMR (400MHz, $\left.\mathrm{CDCl}_{3}\right): \delta 11.50(\mathrm{~s}, 1 \mathrm{H}), 7.75(\mathrm{~s}$, $0.5 \mathrm{H}), 6.40(\mathrm{~s}, 0.5 \mathrm{H}), 5.40-5.25(\mathrm{~m}, 2 \mathrm{H}), 2.10-1.85(\mathrm{~m}, 4 \mathrm{H}), 1.85-1.65(\mathrm{~m}, 2 \mathrm{H}), 1.65-1.50(\mathrm{~m}$, 2H), $1.50-1.15(\mathrm{~m}, 22 \mathrm{H}), 0.85(\mathrm{t}, J=7.0 \mathrm{~Hz}, 3 \mathrm{H}) .{ }^{13} \mathbf{C} \mathbf{N M R}\left(100 \mathrm{MHz}, \mathrm{CDCl}_{3}\right): \delta 130.14$, $129.88,32.07,30.64,30.49,29.93,29.87,29.68,29.47,29.42,29.38,29.26,28.94,27.38$, 27.32, 22.83, 20.71, 14.27. ${ }^{31} \mathbf{P}[\mathbf{1 H}]$ NMR $\left(160 \mathrm{MHz}, \mathrm{CDCl}_{3}\right): \delta 38.83$ ppm. LC-MS (API-ES) calc for $\mathrm{C}_{18} \mathrm{H}_{36} \mathrm{O}_{2} \mathrm{P}[\mathrm{M}-\mathrm{H}]^{-}$315.25, found 135.2.

Synthesis of cadmium $n$-tetradecylphosphinate. The procedure is inspired by the one used to synthesize cadmium oleate of Hendricks et al. ${ }^{15-16,56} \mathrm{CdO}(642.1 \mathrm{mg}, 5 \mathrm{mmol}$, 1eq.) and acetonitrile $(4 \mathrm{~mL})$ are stirred at $0{ }^{\circ} \mathrm{C}$ in an ice bath. Trifluoroacetic anhydride $(708 \mu \mathrm{L}, 5 \mathrm{mmol}$, 1 eq.) and trifluoroacetic acid ( $77 \mu \mathrm{L}, 1 \mathrm{mmol}, 0.2$ eq.) are added and allowed to warm to room temperature and results in a clear and colourless solution overnight, (if the resulting solution would have a white precipitate, a little more acetonitrile or heat results in a clear and colourless solution). This solution is added dropwise to a mixture of $n$-tetradecylphosphinic acid (2636.8 $\mathrm{mg}, 10.05 \mathrm{mmol}, 2.1$ eq.) and triethylamine (1143.5 mg, $11.3 \mathrm{mmol}, 2.25$ eq.) in dichloromethane $(20 \mathrm{~mL})$. The reaction mixture is heated to reflux for an hour. Afterwards, the flask is slowly cooled to room temperature and then put in a freezer. The resulting white powder is filtered on a glass frit and carefully washed by going through the slurry and break-up large chunks three times with cold methanol $(40 \mathrm{~mL})$. The final product is vacuum dried and yields a fine white powder $(4.7 \mathrm{~g}, 93 \%)$. Elemental analysis (CHNS) calc for $\mathrm{C}_{28} \mathrm{H}_{60} \mathrm{O}_{4} \mathrm{P}_{2} \mathrm{Cd}$ : $\% \mathrm{C}$

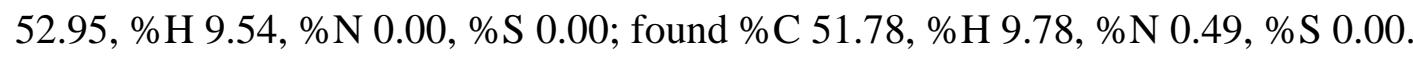


Synthesis of cadmium selenide (CdSe) quantum dots according to Owen et al. ${ }^{26} \mathrm{~A} 50 \mathrm{~mL}$ three neck flask is loaded with cadmium oxide (172.1 mg, $1.34 \mathrm{mmol}, 1.12$ eq.), $n$ octadecylphosphonic acid (752.6 mg, $2.7 \mathrm{mmol}, 2.25$ eq.), and TOPO (15.0 g). The mixture is degassed for 30 minutes at $100{ }^{\circ} \mathrm{C}$. The flask is filled with argon and heated to $330{ }^{\circ} \mathrm{C}$ until the $\mathrm{CdO}$ digests into a colourless solution. Afterwards, the temperature is lowered to $300{ }^{\circ} \mathrm{C}$ at which point $1.3 \mathrm{~mL}$ (1065.0 mg, $1.2 \mathrm{mmol}, 1.00$ eq.) of a premade TOP-Se solution (4.5 mmol Se per 4 gram TOP prepared stirring overnight in an argon filled glovebox) is rapidly injected. After the preferred reaction time, the mixture is cooled down to $60{ }^{\circ} \mathrm{C}$ at which point the QDs are purified 3 times by precipitation with acetone and redispersion in toluene after centrifugation (10k rpm, 10 minutes).

For the synthesis with phosphinic acid or carboxylic acid, we simply replaced $n$ octadecylphosphonic acid by $n$-octadecylphosphinic acid (752.6 mg, $2.7 \mathrm{mmol}, 2.25$ eq.) or oleic acid (762.7 mg, $0.852 \mathrm{~mL}, 2.70 \mathrm{mmol}, 2.25$ eq.) respectively. Since the acidity of the phosphinic and carboxylic acid is slightly lower compared to the phosphonic acid, $\mathrm{CdO}$ is digested at a higher temperature $\left(350{ }^{\circ} \mathrm{C}\right)$ until the colour of the mixture evolved into almost transparent.

Synthesis of cadmium selenide (CdSe) nanorods according Buhro et al. ${ }^{32}$ A $25 \mathrm{~mL}$ three neck flask is loaded with cadmium oxide (51.4 mg, $0.4 \mathrm{mmol}, 1.0$ eq.), di-n-octylphosphinic acid (203.3 mg, $0.7 \mathrm{mmol}, 1.75$ eq.), $n$-tetradecylphosphonic acid (222.7 mg, $0.8 \mathrm{mmol}, 2.0$ eq.), and TOPO (3.8g). The mixture is degassed for 40 minutes at $120{ }^{\circ} \mathrm{C}$. The flask is filled with argon and heated to $320{ }^{\circ} \mathrm{C}$ until the $\mathrm{CdO}$ digests into a colourless solution. Afterwards, the temperature is lowered to $150{ }^{\circ} \mathrm{C}$ for a second degassing step for 1 hour. The flask is filled with argon and heated to $275^{\circ} \mathrm{C}$, at which point $1.2 \mathrm{~mL}$ of a premade TOP-Se solution (3.0 mmol Se per $5 \mathrm{~g}$ TOP prepared stirring overnight in an argon filled glovebox) is rapidly injected. After 30 minutes, the reaction is cooled down to $60{ }^{\circ} \mathrm{C}$ at which point the NRs are purified 3 
times by precipitation with acetone and redispersion in toluene after centrifugation $(10 \mathrm{k} \mathrm{rpm}$, 10 minutes).

For the synthesis with phosphinic acid, we replaced $\mathrm{CdO}$ and $n$-tetradecylphosphonic acid by presynthesized $\mathrm{Cd}(n \text {-tetradecylphosphinate })_{2}(254.1 \mathrm{mg}, 0.4 \mathrm{mmol}, 1.00$ eq. $)$. Since the phosphinic acids ( $n$-tetradecyl and di-n-octyl) have a similar acidity they both digest the $\mathrm{CdO}$ resulting in a white turbid solution.

Cadmium sulfide (CdS) NRs adapted Buhro et al. ${ }^{32}$ Here the same recipe is followed as for the CdSe NRs but where TOP-Se is replaced by TOP-S (3.0 mmol S per 5 gram TOP).

For the synthesis with phosphinic acid, we replaced $\mathrm{CdO}$ and $n$-tetradecylphosphonic acid by presynthesized $\mathrm{Cd}(n \text {-tetradecylphosphinate })_{2}(254.1 \mathrm{mg}, 0.4 \mathrm{mmol}, 1.00 \mathrm{eq}$.$) with a reaction$ time of 1 hour, all other parameters remained identical.

Electron Microscopy. Transmission Electron Microscopy (TEM) and High-Resolution Transmission Electron Microscopy (HRTEM) were performed on a JEOL JEM-2200FS TEM with Cs corrector operated at $200 \mathrm{kV}$ (bright field).

Size and Concentration Determination. The optical band gaps of the NCs were determined by UV-vis-NIR absorption spectroscopy (PerkinElmer Lambda 950). Aliquots of approximately $0.1 \mathrm{~mL}$ were taken from a $\mathrm{CdSe}$ or $\mathrm{CdS}$ nanocrystal reaction and deposited into a previously weighed vial with $3 \mathrm{~mL}$ of hexane. Afterwards, the mixture was further diluted to obtain $10 \mathrm{mg} \mathrm{mL}^{-1}$ reaction mixture solutions in hexane. UV-Vis absorption spectra were taken of each aliquot and the concentration of cadmium selenide in the aliquot was calculated from the size-independent absorption coefficient for CdSe at $340 \mathrm{~nm}\left(\mu=141100 \mathrm{~cm}^{-1}\right)$ reported by Capek et al. ${ }^{50}$ The size of the NCs was determined from the position of the first excitonic absorption peak using the sizing curve described by Maes et al. ${ }^{57}$ 
NMR Spectroscopy. Nuclear Magnetic Resonance (NMR) spectra of the synthesized organics were recorded on a Bruker 300, and $400 \mathrm{MHz}$. Chemical shifts $(\delta)$ are given in ppm and the residual solvent peak was used as an internal standard $\left(\mathrm{CDCl}_{3}: \delta \mathrm{H}=7.24 \mathrm{ppm}, \delta \mathrm{C}=77.06\right.$ ppm, methanol- $\mathrm{D}_{4}: \delta \mathrm{H}=3.31 \mathrm{ppm}, \delta \mathrm{C}=49.00 \mathrm{ppm}, \mathrm{C}_{6} \mathrm{D}_{6}: \delta \mathrm{H}=7.16 \mathrm{ppm}, \delta \mathrm{C}=128.06 \mathrm{ppm}$, toluene- $\left.\mathrm{d}_{8}: \delta \mathrm{H}=2.09 \mathrm{ppm}, \delta \mathrm{C}=20.43 \mathrm{ppm}, \mathrm{C}_{6} \mathrm{D}_{6}: \delta \mathrm{H}=7.16 \mathrm{ppm}, \delta \mathrm{C}=128.06 \mathrm{ppm}\right)$. The signal multiplicity is denoted as follows: s (singlet), $\mathrm{d}$ (doublet), $\mathrm{t}$ (triplet), quad (quadruplet), quin (quintet), m (multiplet). Coupling constants are reported in Hertz (Hz). All resonances were corrected prior to integration by subtracting a background from the measured intensity. Nuclear Magnetic Resonance (NMR) measurements of colloidal nanocrystals were recorded on a Bruker Avance III Spectrometer operating at a ${ }^{1} \mathrm{H}$ frequency of $500.13 \mathrm{MHz}$ and featuring a BBI probe. The sample temperature was set to 298.15 or $313.15 \mathrm{~K}$. For the quantitative $1 \mathrm{D}{ }^{1} \mathrm{H}$ measurements, $64 \mathrm{k}$ data points were sampled with the spectral width set to $16 \mathrm{ppm}$ and a relaxation delay of 30s to allow full relaxation of all NMR signals. The quantification was done by using the Digital ERETIC method. ${ }^{58-59}$ One-dimensional ${ }^{31} \mathrm{P}$ spectra were acquired using the standard pulse sequence aring2 from the Bruker library. DOSY measurements were performed with a double stimulated echo pulses (dstegp3s) for convection compensation and with monopolar gradient pulses. ${ }^{60}$ All resonances were corrected prior to integration by subtracting a background from the measured intensity. The gradient strength was varied quadratically from $2-95 \%$ of the probe's maximum value in 64 steps, with the pulse length gradient (D20) and diffusion time (P30) optimized to ensure a final attenuation of the signal in the final increment of less than $8 \%$ relative to the first increment.

X-ray Diffraction. XRD patterns were collected from a Bruker D8 Discover (with a LynxExe silicon strip detector and $\mathrm{CuK} \alpha$ radiation) in Bragg-Brentano configuration. All samples were scanned from $15^{\circ}$ to $60^{\circ}$ with a step size of $0.02^{\circ}$ and a scan rate of $0.5^{\circ} / \mathrm{min}$. 
Photoluminescence. Photoluminescence spectra were measured upon excitation with a fiber coupled LED (20mA) having a emission peak wavelength of $400 \mathrm{~nm}$. The samples were measured in a Spectralon coated integrating sphere. The emission spectra were analyzed with a fiber coupled Acton SP2300 monochromator and detected by a ProEM 1600 EMCCD (Princeton Instruments). The spectra were properly corrected for the spectral sensitivity of the detector part. The PLQY values were calculated by dividing the integrated number of emitted photons by the number of absorbed photons upon excitation.

Mass spectroscopy. Mass spectra (MS) are measured with an Agilent ESI single quadrupole detector type VL and an Agilent APCI single quadrupole detector type VL.

Elemental Analysis. A Thermo Scientific Flash 2000 CHNS-O analyzer equipped with a TCD detector was used to perform elemental analysis $(\mathrm{C} / \mathrm{H} / \mathrm{N})$.

\section{Acknowledgements}

The authors acknowledge the FWO Vlaanderen (1S28818N), Special Research Fund/Concerted Research Actions project (BOF2015/GOA/007), Ghent University, and Basel University for financial support. The authors thank ing. Jan Goeman for the GC/LC-MS, Olivier Janssens for XRD analysis, and Funda Aliç for elemental analysis.

\section{Associated Content}

\section{Supporting information}

The Supporting Information is available free of charge 


\section{Author Information}

\section{Corresponding Author}

*E-mail: Jonathan.DeRoo@unibas.ch

\section{ORCID}

Evert Dhaene: 0000-0002-1604-0408

Philippe F. Smet: 0000-0003-4789-5799

Klaartje De Buysser: 0000-0001-7462-2484

Jonathan De Roo: 0000-0002-1264-9312

\section{Notes}

The authors declare no competing financial interest.

\section{References}

1. Nanomaterials definition matters. Nature Nanotechnology 2019, 14 (3), 193-193.

2. Boles, M. A.; Ling, D.; Hyeon, T.; Talapin, D. V., The surface science of nanocrystals. Nature Materials 2016, 15 (2), 141-153.

3. Yang, Y.; Qin, H.; Jiang, M.; Lin, L.; Fu, T.; Dai, X.; Zhang, Z.; Niu, Y.; Cao, H.; Jin, Y.; Zhao, F.; Peng, X., Entropic Ligands for Nanocrystals: From Unexpected Solution Properties to Outstanding Processability. Nano Letters 2016, 16 (4), 2133-2138.

4. Yang, Y.; Qin, H.; Peng, X., Intramolecular Entropy and Size-Dependent Solution Properties of Nanocrystal-Ligands Complexes. Nano Letters 2016, 16 (4), 2127-2132.

5. Doblas, D.; Kister, T.; Cano-Bonilla, M.; González-García, L.; Kraus, T., Colloidal Solubility and Agglomeration of Apolar Nanoparticles in Different Solvents. Nano Letters 2019, 19 (8), 5246-5252.

6. Kister, T.; Monego, D.; Mulvaney, P.; Widmer-Cooper, A.; Kraus, T., Colloidal Stability of Apolar Nanoparticles: The Role of Particle Size and Ligand Shell Structure. ACS Nano 2018, 12 (6), 5969-5977. 
7. Monego, D.; Kister, T.; Kirkwood, N.; Doblas, D.; Mulvaney, P.; Kraus, T.; Widmer-Cooper, A., When Like Destabilizes Like: Inverted Solvent Effects in Apolar Nanoparticle Dispersions. ACS Nano 2020, 14 (5), 5278-5287.

8. Monego, D.; Kister, T.; Kirkwood, N.; Mulvaney, P.; Widmer-Cooper, A.; Kraus, T., Colloidal Stability of Apolar Nanoparticles: Role of Ligand Length. Langmuir 2018, 34 (43), 12982-12989.

9. Heuer-Jungemann, A.; Feliu, N.; Bakaimi, I.; Hamaly, M.; Alkilany, A.; Chakraborty, I.; Masood, A.; Casula, M. F.; Kostopoulou, A.; Oh, E.; Susumu, K.; Stewart, M. H.; Medintz, I. L.; Stratakis, E.; Parak, W. J.; Kanaras, A. G., The Role of Ligands in the Chemical Synthesis and Applications of Inorganic Nanoparticles. Chemical Reviews 2019, 119 (8), 4819-4880.

10. Mozaffari, S.; Li, W.; Thompson, C.; Ivanov, S.; Seifert, S.; Lee, B.; Kovarik, L.; Karim, A. M., Colloidal nanoparticle size control: experimental and kinetic modeling investigation of the ligandmetal binding role in controlling the nucleation and growth kinetics. Nanoscale 2017, 9 (36), 13772 13785.

11. Abe, S.; Capek, R. K.; De Geyter, B.; Hens, Z., Reaction Chemistry/Nanocrystal Property Relations in the Hot Injection Synthesis, the Role of the Solute Solubility. ACS Nano 2013, 7 (2), $943-$ 949.

12. Peters, E. H.; Mayor, M., Monofunctionalized Gold Nanoparticles: Fabrication and Applications. Chimia 2021, 75 (5), 414-426.

13. Knauf, R. R.; Lennox, J. C.; Dempsey, J. L., Quantifying Ligand Exchange Reactions at CdSe Nanocrystal Surfaces. Chemistry of Materials 2016, 28 (13), 4762-4770.

14. Li, L.; Daou, T. J.; Texier, I.; Kim Chi, T. T.; Liem, N. Q.; Reiss, P., Highly Luminescent CulnS2/ZnS Core/Shell Nanocrystals: Cadmium-Free Quantum Dots for In Vivo Imaging. Chemistry of Materials 2009, 21 (12), 2422-2429.

15. Hendricks, M. P.; Campos, M. P.; Cleveland, G. T.; Jen-La Plante, I.; Owen, J. S., A tunable library of substituted thiourea precursors to metal sulfide nanocrystals. Science 2015, 348 (6240), 1226-1230.

16. Hamachi, L. S.; Jen-La Plante, I.; Coryell, A. C.; De Roo, J.; Owen, J. S., Kinetic Control over CdS Nanocrystal Nucleation Using a Library of Thiocarbonates, Thiocarbamates, and Thioureas. Chemistry of Materials 2017, 29 (20), 8711-8719.

17. Park, J.; An, K.; Hwang, Y.; Park, J.-G.; Noh, H.-J.; Kim, J.-Y.; Park, J.-H.; Hwang, N.-M.; Hyeon, T., Ultra-large-scale syntheses of monodisperse nanocrystals. Nature Materials 2004, 3 (12), 891-895.

18. García-Rodríguez, R.; Hendricks, M. P.; Cossairt, B. M.; Liu, H.; Owen, J. S., Conversion Reactions of Cadmium Chalcogenide Nanocrystal Precursors. Chemistry of Materials 2013, 25 (8), 1233-1249.

19. De Roo, J.; De Keukeleere, K.; Hens, Z.; Van Driessche, I., From ligands to binding motifs and beyond; the enhanced versatility of nanocrystal surfaces. Dalton Transactions 2016, 45 (34), 1327713283.

20. Leemans, J.; Dümbgen, K. C.; Minjauw, M. M.; Zhao, Q.; Vantomme, A.; Infante, I.; Detavernier, C.; Hens, Z., Acid-Base Mediated Ligand Exchange on Near-Infrared Absorbing, Indium-Based III-V Colloidal Quantum Dots. Journal of the American Chemical Society 2021, 143 (11), 4290-4301.

21. Oliva-Puigdomènech, A.; De Roo, J.; Kuhs, J.; Detavernier, C.; Martins, J. C.; Hens, Z., Ligand Binding to Copper Nanocrystals: Amines and Carboxylic Acids and the Role of Surface Oxides. Chemistry of Materials 2019, 31 (6), 2058-2067.

22. Gomes, R.; Hassinen, A.; Szczygiel, A.; Zhao, Q.; Vantomme, A.; Martins, J. C.; Hens, Z., Binding of Phosphonic Acids to CdSe Quantum Dots: A Solution NMR Study. The Journal of Physical Chemistry Letters 2011, 2 (3), 145-152.

23. De Roo, J.; Zhou, Z.; Wang, J.; Deblock, L.; Crosby, A. J.; Owen, J. S.; Nonnenmann, S. S., Synthesis of Phosphonic Acid Ligands for Nanocrystal Surface Functionalization and Solution Processed Memristors. Chemistry of Materials 2018, 30 (21), 8034-8039.

24. De Roo, J.; Huang, Z.; Schuster, N. J.; Hamachi, L. S.; Congreve, D. N.; Xu, Z.; Xia, P.; Fishman, D. A.; Lian, T.; Owen, J. S.; Tang, M. L., Anthracene Diphosphate Ligands for CdSe Quantum Dots; Molecular Design for Efficient Upconversion. Chemistry of Materials 2020, 32 (4), 1461-1466. 
25. Nemat, S. J.; Van den Eynden, D.; Deblock, L.; Heilmann, M.; Köster, J. M.; Parvizian, M.; Tiefenbacher, K.; De Roo, J., Resorcin[4]arene-based multidentate phosphate ligands with superior binding affinity for nanocrystal surfaces. Chemical Communications 2021, 57 (38), 4694-4697.

26. Owen, J. S.; Park, J.; Trudeau, P.-E.; Alivisatos, A. P., Reaction Chemistry and Ligand Exchange at Cadmium-Selenide Nanocrystal Surfaces. Journal of the American Chemical Society 2008, 130 (37), 12279-12281.

27. Peng, Z. A.; Peng, X., Formation of High-Quality CdTe, CdSe, and CdS Nanocrystals Using CdO as Precursor. Journal of the American Chemical Society 2001, 123 (1), 183-184.

28. Carbone, L.; Nobile, C.; De Giorgi, M.; Sala, F. D.; Morello, G.; Pompa, P.; Hytch, M.; Snoeck, E.; Fiore, A.; Franchini, I. R.; Nadasan, M.; Silvestre, A. F.; Chiodo, L.; Kudera, S.; Cingolani, R.; Krahne, R.; Manna, L., Synthesis and Micrometer-Scale Assembly of Colloidal CdSe/CdS Nanorods Prepared by a Seeded Growth Approach. Nano Letters 2007, 7 (10), 2942-2950.

29. Zhang, B.; Goldoni, L.; Zito, J.; Dang, Z.; Almeida, G.; Zaccaria, F.; de Wit, J.; Infante, I.; De Trizio, L.; Manna, L., Alkyl Phosphonic Acids Deliver CsPbBr3 Nanocrystals with High Photoluminescence Quantum Yield and Truncated Octahedron Shape. Chemistry of Materials 2019, 31 (21), 9140-9147.

30. Drijvers, E.; De Roo, J.; Geiregat, P.; Fehér, K.; Hens, Z.; Aubert, T., Revisited Wurtzite CdSe Synthesis: A Gateway for the Versatile Flash Synthesis of Multishell Quantum Dots and Rods. Chemistry of Materials 2016, 28 (20), 7311-7323.

31. Jin, H.; Goryca, M.; Janicke, M. T.; Crooker, S. A.; Klimov, V. I., Exploiting Functional Impurities for Fast and Efficient Incorporation of Manganese into Quantum Dots. Journal of the American Chemical Society 2020.

32. Wang, F.; Buhro, W. E., Morphology Control of Cadmium Selenide Nanocrystals: Insights into the Roles of Di-n-octylphosphine Oxide (DOPO) and Di-n-octylphosphinic Acid (DOPA). Journal of the American Chemical Society 2012, 134 (11), 5369-5380.

33. Wang, F.; Tang, R.; Buhro, W. E., The Trouble with TOPO; Identification of Adventitious Impurities Beneficial to the Growth of Cadmium Selenide Quantum Dots, Rods, and Wires. Nano Letters 2008, 8 (10), 3521-3524.

34. Wang, F.; Tang, R.; Kao, J. L. F.; Dingman, S. D.; Buhro, W. E., Spectroscopic Identification of Trin-octylphosphine Oxide (TOPO) Impurities and Elucidation of Their Roles in Cadmium Selenide Quantum-Wire Growth. Journal of the American Chemical Society 2009, 131 (13), 4983-4994.

35. Kloda, M.; Ondrušová, S.; Lang, K.; Demel, J., Phosphinic acids as building units in materials chemistry. Coordination Chemistry Reviews 2021, 433, 213748.

36. Shynkarenko, Y.; Bodnarchuk, M. I.; Bernasconi, C.; Berezovska, Y.; Verteletskyi, V.; Ochsenbein, S. T.; Kovalenko, M. V., Direct Synthesis of Quaternary Alkylammonium-Capped Perovskite Nanocrystals for Efficient Blue and Green Light-Emitting Diodes. ACS Energy Letters 2019, 4 (11), 2703-2711.

37. Anderson, N. C.; Chen, P. E.; Buckley, A. K.; De Roo, J.; Owen, J. S., Stereoelectronic Effects on the Binding of Neutral Lewis Bases to CdSe Nanocrystals. Journal of the American Chemical Society 2018, 140 (23), 7199-7205.

38. De Nolf, K.; Cosseddu, S. M.; Jasieniak, J. J.; Drijvers, E.; Martins, J. C.; Infante, I.; Hens, Z., Binding and Packing in Two-Component Colloidal Quantum Dot Ligand Shells: Linear versus Branched Carboxylates. Journal of the American Chemical Society 2017, 139 (9), 3456-3464.

39. Karanewsky, D. S.; Badia, M. C.; Cushman, D. W.; DeForrest, J. M.; Dejneka, T.; Loots, M. J.; Perri, M. G.; Petrillo, E. W., Jr.; Powell, J. R., (Phosphinyloxy)acyl amino acid inhibitors of angiotensin converting enzyme (ACE). 1. Discovery of (S)-1-[6-amino-2-[[hydroxy(4-phenylbutyl)phosphinyl]oxy]1-oxohexyl]-L -proline a novel orally active inhibitor of ACE. J Med Chem 1988, 31 (1), 204-12.

40. Troupa, P.; Katsiouleri, G.; Vassiliou, S., Rapid and Efficient Microwave-Assisted Hydrophosphinylation of Unactivated Alkenes with H-Phosphinic Acids without Added Metal or Radical Initiator. Synlett 2015, 26 (19), 2714-2719.

41. Montchamp, J.-L., Phosphinate Chemistry in the 21st Century: A Viable Alternative to the Use of Phosphorus Trichloride in Organophosphorus Synthesis. Accounts of Chemical Research 2014, 47 (1), 77-87. 
42. Deprèle, S.; Montchamp, J.-L., Triethylborane-Initiated Room Temperature Radical Addition of Hypophosphites to Olefins: Synthesis of Monosubstituted Phosphinic Acids and Esters. The Journal of Organic Chemistry 2001, 66 (20), 6745-6755.

43. Sytniczuk, A.; Dąbrowski, M.; Banach, Ł.; Urban, M.; Czarnocka-Śniadała, S.; Milewski, M.; Kajetanowicz, A.; Grela, K., At Long Last: Olefin Metathesis Macrocyclization at High Concentration. Journal of the American Chemical Society 2018, 140 (28), 8895-8901.

44. Appel, R., Tertiary Phosphane/Tetrachloromethane, a Versatile Reagent for Chlorination, Dehydration, and P-N Linkage. Angewandte Chemie International Edition in English 1975, 14 (12), 801 811.

45. M. Crawforth, J.; Fawcett, J.; J. Rawlings, B., Asymmetric synthesis of A-factor. Journal of the Chemical Society, Perkin Transactions 1 1998, (10), 1721-1726.

46. Jia, X.; Weber, S.; Schols, D.; Meier, C., Membrane Permeable, Bioreversibly Modified Prodrugs of Nucleoside Diphosphate- $\gamma$-Phosphonates. Journal of Medicinal Chemistry 2020, 63 (20), 1199012007.

47. Edmundson, R. S., Properties and Reactions of Phosphonic and Phosphinic Acids and their Derivatives. In PATAI'S Chemistry of Functional Groups.

48. De Roo, J.; Yazdani, N.; Drijvers, E.; Lauria, A.; Maes, J.; Owen, J. S.; Van Driessche, I.; Niederberger, M.; Wood, V.; Martins, J. C.; Infante, I.; Hens, Z., Probing Solvent-Ligand Interactions in Colloidal Nanocrystals by the NMR Line Broadening. Chemistry of Materials 2018, 30 (15), 5485-5492. 49. Abe, S.; Čapek, R. K.; De Geyter, B.; Hens, Z., Tuning the Postfocused Size of Colloidal Nanocrystals by the Reaction Rate: From Theory to Application. ACS Nano 2012, 6 (1), 42-53.

50. Karel Čapek, R.; Moreels, I.; Lambert, K.; De Muynck, D.; Zhao, Q.; Van Tomme, A.; Vanhaecke, F.; Hens, Z., Optical Properties of Zincblende Cadmium Selenide Quantum Dots. The Journal of Physical Chemistry C 2010, 114 (14), 6371-6376.

51. Owen, J. S.; Chan, E. M.; Liu, H.; Alivisatos, A. P., Precursor Conversion Kinetics and the Nucleation of Cadmium Selenide Nanocrystals. Journal of the American Chemical Society 2010, 132 (51), 18206-18213.

52. McMurtry, B. M.; Qian, K.; Teglasi, J. K.; Swarnakar, A. K.; De Roo, J.; Owen, J. S., Continuous Nucleation and Size Dependent Growth Kinetics of Indium Phosphide Nanocrystals. Chemistry of Materials 2020, 32 (10), 4358-4368.

53. Whitehead, C. B.; Özkar, S.; Finke, R. G., LaMer's 1950 Model for Particle Formation of Instantaneous Nucleation and Diffusion-Controlled Growth: A Historical Look at the Model's Origins, Assumptions, Equations, and Underlying Sulfur Sol Formation Kinetics Data. Chemistry of Materials 2019, 31 (18), 7116-7132.

54. Prins, P. T.; Montanarella, F.; Dümbgen, K.; Justo, Y.; van der Bok, J. C.; Hinterding, S. O. M.; Geuchies, J. J.; Maes, J.; De Nolf, K.; Deelen, S.; Meijer, H.; Zinn, T.; Petukhov, A. V.; Rabouw, F. T.; De Mello Donega, C.; Vanmaekelbergh, D.; Hens, Z., Extended Nucleation and Superfocusing in Colloidal Semiconductor Nanocrystal Synthesis. Nano Letters 2021, 21 (6), 2487-2496.

55. Williams, D. B. G.; Lawton, M., Drying of Organic Solvents: Quantitative Evaluation of the Efficiency of Several Desiccants. The Journal of Organic Chemistry 2010, 75 (24), 8351-8354.

56. Dhaene, E.; Billet, J.; Bennett, E.; Van Driessche, I.; De Roo, J., The Trouble with ODE: Polymerization during Nanocrystal Synthesis. Nano Letters 2019, 19 (10), 7411-7417.

57. Maes, J.; Castro, N.; De Nolf, K.; Walravens, W.; Abécassis, B.; Hens, Z., Size and Concentration Determination of Colloidal Nanocrystals by Small-Angle X-ray Scattering. Chemistry of Materials 2018, 30 (12), 3952-3962.

58. Akoka, S.; Barantin, L.; Trierweiler, M., Concentration Measurement by Proton NMR Using the ERETIC Method. Analytical Chemistry 1999, 71 (13), 2554-2557.

59. Silvestre, V.; Goupry, S.; Trierweiler, M.; Robins, R.; Akoka, S., Determination of Substrate and Product Concentrations in Lactic Acid Bacterial Fermentations by Proton NMR Using the ERETIC Method. Analytical Chemistry 2001, 73 (8), 1862-1868. 
60. Connell, M. A.; Bowyer, P. J.; Adam Bone, P.; Davis, A. L.; Swanson, A. G.; Nilsson, M.; Morris, G. A., Improving the accuracy of pulsed field gradient NMR diffusion experiments: Correction for gradient non-uniformity. Journal of Magnetic Resonance 2009, 198 (1), 121-131. 